\title{
LITERATURA ÁRABE Y POSMODERNIDAD: EL JUEGO DE LA MUERTE EN DUNIAZAD, DE MAY TILMISANI
}

\author{
$M^{a}$ Dolores López Enamorado \\ Universidad de Sevilla
}

\begin{abstract}
RESUMEN
En la literatura árabe actual se están produciendo unos cambios de enorme interés. Los autores exploran nuevos caminos, alejados de la concepción tradicional de la narrativa árabe, en la que el realismo, el costumbrismo, y un marcado tinte social y político eran las notas más destacadas. Hoy, la narrativa explora formas nuevas, algunas de las cuales, en este caso los rasgos de la posmodernidad, son analizadas en este trabajo. En él se aborda el estudio de la más joven narrativa egipcia, representada aqui por May Tilmisani, una de las figuras más destacadas de esta nueva generación de escritores egipcios.

Palabras clave: Literatura árabe contemporánea, Narrativa, Egipto, Posmodernidad, Novela árabe.
\end{abstract}

ABSTRACT

Arabic contemporary literature is experiencing changes of great interest. Writers explore new ways, far from the traditional paradigms of Arabic narrative, in which realism, costumbrism and a sharp social and political tone were their main characteristics. Today this narrative explores new forms, some of them, in this case its postmodern imprint, are analyzed in this paper. The article focuses on the youngest Egyptian narrative, represented here by May Tilmisani, one of the most representative figures of this new generation of Egyptian writers.

Keywords: Arabic contemporary literature, Narrative, Egypt, Postmodernity, Arabic novel. 
Escribo Duniazad e invoco las letras de su nombre para olvidar May Tilmisani. Duniazad He abandonado la lectura y la escritura; ya no sé quién soy;
mi nombre no es más que un manojo de letras, igual que toda la literatura:
tiras de letras y espacios vacíos,
un código para el que no encuentro clave alguna
John Barth. "Dunyazadiad". Quimera

En los manuales e historias de la literatura árabe encontramos a menudo referencias a algunos "post": post-romanticismo o post-guerra, por poner un par de ejemplos. Sin embargo parece que el término posmodernidad o el adjetivo posmoderno no acaban de encajar con el panorama literario del mundo árabe actual.

Por ello, antes de analizar los posibles rasgos posmodernos de la novela que he elegido, Duniazad, de la escritora egipcia May Tilmisani ${ }^{1}$, considero conveniente hacer un breve recorrido por una de las narrativas contemporáneas más desconocidas: la narrativa árabe, y, dentro de ella, la literatura egipcia, en muchos casos abriendo nuevos caminos.

Sin duda Duniazad es una novela egipcia, porque egipcia es su autora y egipcios son sus personajes. Esto tan evidente es, en lo relativo a la literatura árabe, un fenómeno relativamente reciente, ya que la novela egipcia no se "egipcianiza", es decir, no tiene rasgos propios, hasta las primeras décadas del siglo XX, y en un proceso muy lento al que aludiré más abajo. Desde entonces -y Naguib Mahfuz es buena prueba de ello- ya no se plantean estas cuestiones. Duniazad es una novela egipcia, en efecto; pero es, en mi opinión, un error, clasificarla en una corriente étnica, considerarla como una de esas novelas que plasman mundos exóticos, que nos trasportan a realidades situadas en contextos que no nos son familiares. Y eso es, lisa y llanamente, porque Duniazad habla de lo esencial, de lo universal, de lo que es común al ser humano: el dolor por la muerte. Sin folklorismos, sin exotismo, sin sumergirnos en lo que el lector occidental común espera recibir de una novela árabe. Porque ése es uno de los

\footnotetext{
${ }^{1}$ Publicada en El Cairo, Šarqiyyât, 1997. Traducción española de Gonzalo Fernández Parrilla (Guadarrama, Ediciones del Oriente y del Mediterráneo, 2001). Las referencias que hago en este trabajo van referidas a la edición española. G. Fernández Parrilla, en su trabajo "Alteridades idénticas a nosotros mismo: una experiencia de traducción", Asparkí, XIII (2002), pp. 55-59, hace una interesante reflexión sobre su experiencia como traductor de este obra, acompañada de anotaciones imprescindibles para acercarse a ella; para comprender el texto y el contexto.
} 
escollos que tiene que salvar aún hoy la literatura árabe: el de quitarse de encima esa losa de exotismo, de realismo local, de narración costumbrista que fue tan característica en años precedentes y que aún hoy se sigue cultivando por un buen número de escritores. El escritor egipcio actual -el escritor árabe en general- se ve obligado a tomar una importante decisión: cubrir las expectativas del público lector y hacer una literatura de consumo colectivo, generalizado, amplio; o meterse por derroteros diferentes, romper moldes y, por tanto, arriesgarse al anonimato, condenarse al ostracismo. Porque, ¿para qué lo vamos a negar?, al menos en lo que se refiere a los gustos del lector occidental, éste, cuando compra una novela árabe traducida a su lengua, en general espera que el autor lo transporte al Oriente que predomina en el imaginario occidental, al mundo tópico de velos, harenes, elementos de la religión islámica, sándalo, patriarcado, enclaustramiento de la mujer..., que sí existe, pero que convive con ese otro Oriente universitario, feminista, moderno, posmoderno, innovador, vanguardista, laico, y muy alejado de lo que consideraríamos exótico.

Ahí entramos en un terreno enormemente complejo y lleno de ramificaciones, muchas de ellas de candente actualidad. Me refiero a la concepción del mundo actual en dos polos claramente diferenciados, al menos para algunos: mundo cristiano-occidental y mundo árabe-islámico. Ambos son los protagonistas de esta gran puesta en escena. El resto son actores secundarios de este drama que parte de la necesidad de un Otro para legitimar y afianzar la propia identidad, que es, ante todo, una cuestión de símbolos y apariencias ${ }^{2}$. Soy lo que soy porque hay otro que no es lo que yo soy, o que es lo que yo no soy. Un complejo juego del lenguaje que no hace más que reflejar el complejo juego de la alta política. Ese Otro lo es, precisamente, porque yo así lo percibo, independientemente de que él sea consciente de ser el Otro o de ser distinto de mí. Unos versos de Antonio Machado, salvando las distancias, resumen para mí esta circunstancia:

El ojo que ves

no es ojo porque tú lo veas;

es ojo porque te ve. ${ }^{3}$

El mundo árabe existe; con sus diversas leyes, gobiernos, estilos de vida, y personas. $\mathrm{Y}$ existe y tiene una identidad (o muchas identidades) propia,

${ }^{2}$ Ver en este sentido la interesante obra de A. Maaluf, Identidades Asesinas (Madrid, Alianza Editorial, 1999).

${ }^{3}$ A. Machado, "Proverbios y Cantares", en Nuevas Canciones (Madrid, 1924). 
independientemente de la definición externa que de él se haga. Evidentemente no es un todo homogéneo, no es una unidad, ni una sola religión, ni unos rasgos fenotípicos, ni una actitud ante la vida, ni una sola sociedad, ni un sistema político único... Es una pluralidad en todos los aspectos. Al igual que Occidente, que tampoco es una única realidad sino un concepto que designa muchas y diferentes realidades. En ese caso, ¿cuál es la definición de Occidente? ¿En qué se asemeja o se distingue un sevillano de un danés, por poner un ejemplo? ¿Y qué diferencia o qué similitud existe entre un egipcio y una cordobesa? ¿Son palabras antónimas? ¿Tienen significado estas contraposiciones de términos? ¿Quién soy yo y quién es el Otro? Muchos parecen tenerlo claro: para ellos, y al menos hoy por hoy, Yo es el Occidente civilizado, democrático, cristiano y capitalista. Y sabemos quién es, en general, calificado como el Otro.

En el terreno político esta polarización es la fuente de las mayores tensiones de nuestro tiempo: las Guerras del Golfo, la guerra en Yugoslavia, los atentados del 11 de septiembre de 2001 en Estados Unidos, las continuas guerras y amenazas sobre Iraq, el temor europeo ante la inmigración del Sur y ante el crecimiento del fundamentalismo islámico, la eterna desconfianza de unos frente a otros.

Añado sólo una reflexión más en este sentido: ambos mundos, Occidente y el mundo árabe, han evolucionado de forma completamente diferente, al igual que diferente ha sido el contexto socio-político, económico, cultural... en ambas zonas durante el siglo XX (y las épocas anteriores). Si, por señalar una fecha, la posmodernidad tiene su nacimiento en la Francia de los años $60^{4}$, no debemos olvidar que esa década, y la anterior, es, en el Oriente Medio y el Magreb, la época de la descolonización. Y, por centrarnos en Egipto, aunque el gobierno británico reconoce la soberanía e independencia del país en 1922, esto no conllevó el final efectivo del Protectorado ni la salida de los soldados británicos de Egipto $^{5}$, que no lo abandonaron definitivamente hasta mediados los años 50.

${ }^{4}$ Ver al respecto la detallada cronología que hace A. Quevedo, De Foucault a Derrida. Pasando fugazmente por Deleuze y Guattari, Lyotard, Baudrillard (Barañáin, Ediciones Universidad de Navarra, 2001), pp. 15-20. La misma autora señala (p.17) que quien realmente consagra y difunde el término es Jean-François Lyotard en su obra La condición posmoderna (1979).

${ }^{5}$ La Declaración del Gobierno Británico para Egipto, de 28 de febrero de 1922, otorga al país una independencia restringida, ya que los británicos se reservaban cuatro puntos de vital importancia: la seguridad de las comunicaciones del Imperio en Egipto, la defensa de Egipto contra toda agresión exterior, la protección de los intereses extranjeros y las minorías en el país, y la cuestión del Sudán. Estas capitulaciones no fueron abolidas hasta 
Unas coordenadas, como puede apreciarse, bien distintas de las europeas ${ }^{6}$. Nada de esto es, evidentemente, literatura; pero la literatura es siempre reflejo de la sociedad en la que surge, en la que se desarrolla y en la que basa su experiencia. Y todo lo que he dicho anteriormente puede ser aplicado sin grandes esfuerzos al terreno literario. La crítica literaria y el lector occidental se acercan generalmente a la literatura árabe con unos esquemas y unos condicionamientos previos, basados en lo que ya se conoce, en la propia experiencia (quiero aclarar aquí que entiendo por literatura árabe la escrita por autores árabes en lengua árabe). Así, se espera encontrar una literatura esencialmente costumbrista, en la que la otredad quede de manifiesto, en la que se aprecie claramente la diferencia, ya sea en las relaciones entre personas, en la historia que se cuenta, en los personajes dibujados, en los escenarios, etc.

La literatura egipcia contemporánea más conocida en España puede reducirse básicamente a las obras fundamentales de Naguib Mahfuz, autor ampliamente difundido gracias a la concesión del Premio Nobel de Literatura en 1988. Se está haciendo un importantísimo esfuerzo por parte de los traductores y de los editores $^{7}$ para sacar a la luz obras actuales, pero por el momento el público lector es muy reducido. Así, insisto, el lector común va a lo que conoce: a aquellas obras de la literatura árabe contemporánea en las que sabe que encontrará lo que busca, que, como ya he señalado, es sobre todo exotismo.

1937. Ver G. Martín Muñoz, Política y elecciones en el Egipto contemporáneo (Madrid, Agencia Española de Cooperación Internacional, 1992); $M^{\text {a }}$ D. López Enamorado, $E l$ Egipto contemporáneo de Naguib Mahfuz. La bistoria en la Trilogía (Sevilla, Alfar-Ixbilia, 1999).

${ }^{6}$ Aunque orientado a la literatura hispanoamericana, me ha interesado mucho el trabajo de E. von der Walde, "Realismo mágico y poscolonialismo: construcciones del otro desde la otredad", en S. Castro-Gómez y E. Mendieta (eds.) Teorías sin disciplina (latinoamericanismo, poscolonialidad y globalización en debate) (México, Ed. Miguel Ángel Porrúa, 1998). En <http://ensayo.rom.uga.edu/critica/teoria/castro/walde.htm> (última consulta: 07.07.06).

${ }^{7}$ Quiero destacar aquí la importante labor desarrollada por Ediciones del Oriente y del Mediterráneo, cuyo trabajo incluye un dilatado número de obras de la literatura árabe contemporánea traducidas al castellano, entre ellas la novela Duniazad, de May Tilmisani, que es objeto de este estudio. Buena prueba de esta labor es su catálogo de publicaciones, que puede consultarse en:

$<$ http://www.webdoce.com/orienteymediterraneo $>$ (última consulta: 07.07.06). 


\section{SITUACIÓN DE LA NARRATIVA EGIPCIA HOY.}

Sin embargo, poco o nada de esto hallará este lector en la narrativa egipcia más reciente. Me refiero a las novelas y cuentos producidos por una nueva generación de escritores, nacidos en los años 60, cuyas obras empiezan a ser publicadas a partir de 1995. Una buena parte de la crítica árabe ha denominado a esta generación con el adjetivo de "post-mahfuzí", algo que matizan los propios escritores que la integran: Reconocen ser deudores de escritores de la talla de Mahfuz, pero se alejan considerablemente de la concepción que éstos tienen de la narrativa y de la escritura en general ${ }^{8}$. Esta nueva generación de escritores rompe radicalmente con las normas tradicionales de la narrativa, y con la representación realista de la realidad, algo que era uno de los sellos característicos de la narrativa árabe anterior. Esta ruptura es, a la vez, uno de los rasgos específicos de la posmodernidad. Muntasir al-Qaffâs, destacado representante de esta generación, señala al respecto que "todas las ideologías árabes fracasaron ante ellos en su interpretación de la realidad, o incluso en sus intentos de cambiarla. De ahí que estos escritores jóvenes no puedan -o no quieran- escribir un relato o una novela con la construcción y las formas tradicionales"

Queda aquí puesta de manifiesto una actitud de hastío y desorientación muy cercana a la actitud occidental posmoderna. Porque los condicionamientos actuales son en cierta forma similares, ya que la producción de estos autores se enmarca en el Egipto de Mubarak, "en una época de alocadas contradicciones económicas, democráticas, ideológicas y hasta culturales, los espacios de expresión se amplían, dando cabida a curiosas síntesis cuya viabilidad está aún por verificar. En el caso de la literatura, los enconados debates a que han dado lugar algunas publicaciones recientes son, cuando menos, exponente de una efervescencia desconocida en las últimas décadas. Igualmente el crecimiento y diversificación del campo editorial favorece la difusión de textos y autores de nuevo cuño" ${ }^{10}$. La pregunta es: ¿puede calificarse a estos autores como posmodernos? $\mathrm{O}$, yendo aún más lejos: ¿los condicionamientos de todo tipo hacen que la posmodernidad sea posible en el mundo árabe?

\footnotetext{
${ }^{8}$ He estudiado la obra de Muntasir al-Qaffâš, uno de los representantes de esta nueva generación de narradores, de cuya producción detallo los rasgos esenciales en: $\mathrm{M}^{\mathrm{a}} \mathrm{D}$. López Enamorado, "Muntasir al-Qaffâs y la nueva narrativa egipcia", Philologia Hispalensis, XIV/2 (2000) (Homenaje a la profesora Eugenia Gálvez Vázquez), pp. 301-307.

${ }^{9}$ López Enamorado, “Muntasir...”, p. 304.

${ }^{10}$ L. Gómez García, "Nueva narrativa egipcia; presentación y entrevista", Nación Árabe, 45, año XV (verano 2001), p. 137.
} 


\section{POSMODERNIDAD Y MUNDO ÁRABE.}

Entre las múltiples, variadas y heterogéneas definiciones que de posmodernismo he consultado, son realmente escasas las que se refieren en algún momento al mundo árabe ${ }^{11}$. En ellas se habla de Occidente, movimiento en Occidente, estética o moda de Occidente... Y ya hemos visto que, en principio, este Occidente excluye a lo árabe, al Oriente.

La recepción de la posmodernidad en el Tercer Mundo es ampliamente estudiada en lo relativo a América Latina, y tratada de pasada en cuanto a India, Turquía, Kenya o el sudeste asiático (sobre todo en cuanto a fusión de géneros musicales). ¿Qué ocurre con la literatura del amplísimo mundo árabe? ¿Por qué no se habla de él? La obra Posmodernismo para principiantes curiosamente sí se refiere de pasada a este tema, aunque da por zanjada la cuestión en un sola frase: "El Islam y el llamado Tercer Mundo no son tenidos en cuenta en las descripciones del posmodernismo" ${ }^{12}$. Y no sólo eso: un ejemplo concreto y actual del olvido del Otro, al que me refería con anterioridad, lo tenemos en los buscadores de Internet (en este caso recurro a Google), que localizan varios cientos de entradas con la clave de búsqueda "novela posmoderna", entradas que se reducen drásticamente cuando a esas palabras se añade la especificación "árabe".

La posmodernidad no ha llegado al mundo árabe, o al menos no se ha instalado en él como lo ha hecho en Occidente. Las razones son obvias, y parten de los condicionamientos políticos, sociales, culturales, que han actuado sobre los países árabes para que en ellos se dé, en múltiples aspectos, una evolución diferente de la que se ha dado en Europa. Quiero destacar, entre ellos, el momento y la circunstancia del nacimiento de la novela árabe, cuestión ampliamente tratada por los estudiosos ${ }^{13}$. Hay que esperar a 1914 para que se

${ }^{11}$ La bibliografía concreta sobre el tema es igualmente escasa. Entre las referencias, destaco aquí la obra de K. Abdel-Malek y W. Hallaq (eds.), Tradition, modernity, and postmodernity in Arabic literature: essays in honor of Professor Issa J. Boullata (Leiden, Brill, 2000).

${ }^{12}$ R. Appignanesi y C. Garratt, Posmodernismo para principiantes (Buenos Aires, Era Naciente, 1997), p. 160.

${ }^{13}$ A modo de orientación cito algunos trabajos útiles para el tema: R. Allen, The Arabic novel. An historical and critical introduction (Manchester, University of Manchester, 1982. Segunda edición: Syracusa, Nueva York, Syracuse University Press, 1995). M. del Amo Hernández, "El nacimiento de la novela egipcia: antecedentes", Miscelánea de Estudios Árabes y Hebraicos, 31 (1982), pp. 61-78. S. Hafez, The genesis of Arabic narrative 
publique la que es considerada comúnmente ${ }^{14}$ como la primera novela árabe. Se trata de Zaynab de Muhammad Husayn Haykal. Baste un dato para entender que la evolución de este género no corre paralela en el mundo árabe y en el mundo occidental: las que se consideran como primeras novelas europeas son $E l$ Lazarillo y El Quijote, fechadas respectivamente en 1554 y 1605. Son éstas "las dos novelas 'modernas' que abren y llevan a la perfección el género novela en la cultura europea" 15 . La génesis de la novela europea se produce, por tanto, con al menos tres siglos de antelación respecto del surgimiento de este género en la literatura árabe. Sin embargo, y curiosamente, ambas nacen en una etapa que se designa con términos equivalentes. En árabe se denomina ${ }^{c} A b d$ al-ŶYmūd, que significa literalmente época del estancamiento, del anquilosamiento, a la etapa comprendida entre los siglos XIII y XIX. A ella le sigue lo que en árabe se denomina la Nabda, el despertar, el levantarse, para cuyo estudio se toma como fecha convencional de inicio el año 1798 . Y es en la Nabda donde se sitúa el surgimiento de la novela árabe. Por su parte, en Europa a la Edad Media (la época de las tinieblas, o los siglos oscuros) le sigue el Renacimiento (y el Humanismo), allá por el siglo XV. Y es en estas dos etapas designadas con términos semejantes, la Nabda árabe y el Renacimiento europeo, en las que nace la novela moderna. Sólo que, repito, con al menos tres siglos de diferencia.

Todo este análisis, en mi opinión necesario, nos lleva de nuevo a la cuestión central de este trabajo: Si la evolución de la novela europea es tan marcadamente distinta a la de la novela árabe, ¿puede esta última haber pasado por las mismas

discourse. A study in the sociology of modern Arabic literature (Londres, Saqi Books, 1993). P. Martínez Montávez, Introducción a la literatura árabe moderna (Madrid, CantArabia, 1985). M. Moosa, The origins of modern Arabic fiction (Boulder-Londres, Lynne Rienner Publishers, 1997²). Ch. Vial, "Contribution à l'étude du roman et de la nouvelle en Égypte des origines à 1960", Revue de l'Occident Musulman et de la Méditerranée, 4 (1967), pp. 133-174. M $\mathrm{M}^{\mathrm{a}} \mathrm{J}$. Viguera, "Esquema de la novela árabe contemporánea", Revista de la Universidad Complutense, XXV, $\mathrm{n}^{\circ} 103$ (mayo-junio, 1976), pp. 131-180. 'A. M. Taha Badr, Tatawwur al-riwayya al-'arabiyya al-hadiț fi-Misr (El Cairo, Dar al-Macârif, 1963). $\mathrm{M}^{\mathrm{a}} \mathrm{D}$. López Enamorado, "Panorama general de la novela árabe desde sus orígenes a Mahfûz”, en S. Serour (coord.), Lingüistica y literatura árabes (Vitoria, Artegarin, 2002), pp. 13-41.

${ }^{14}$ La polémica centrada en decidir si la primera novela árabe es Zaynab, o Adra Dinšarway de Mahmud Tahir Haqqi, no es relevante aquí, ya que esta última apareció con pocos años de antelación, en 1906.

${ }^{15} \mathrm{M}^{\mathrm{a}}$ C. Bobes Naves, La novela (Madrid, Síntesis, 1993), p. 70. 
etapas y hallarse ahora en momentos similares? $\mathrm{O}$, concretando aún más: ¿Hay rasgos posmodernos en la novela árabe?

Apuntaba más arriba que la posmodernidad no ha llegado al mundo árabe, o al menos no se ha instalado en él como lo ha hecho en Occidente. Sin embargo sería absurdo negar que esta posmodernidad tan occidental se ha filtrado en los autores de las generaciones más jóvenes, a través de sus lecturas, estancias y formación en el extranjero, televisión vía satélite y, por supuesto, a través de Internet. El cyber-espacio no conoce barreras (al menos en Egipto; en otros países el acceso a la red está prohibido, restringido o al menos controlado). Las nuevas ideologías, los nuevos planteamientos estéticos, todo, absolutamente todo, se ha convertido en producto de consumo en un hipermercado inmenso en el que los árabes, como los europeos, como el resto de la humanidad, son consumidores imparables.

Así, esta nueva generación de los noventa, que conoce bien las literaturas y modas estéticas europeas, y a la que May Tilmisani pertenece, tiene unos planteamientos que difieren notablemente de los de sus predecesores. Voy a tratar de resumirlos brevemente a partir de sus propias opiniones y manifestaciones ${ }^{16}$ :

- Respecto a la longitud de las obras, se aprecia en esta generación una tendencia clara al relato o a la novela breve, en un intento de evitar en la escritura todo lo superfluo. Estos jóvenes narradores se oponen a "las digresiones, la reconstrucción total de un ambiente o la elaboración de personajes con una caracterización inicial muy marcada y que mediante apreciaciones y comentarios lógicos van desarrollándose hasta el desenlace final” (Qaffáx).

- En esta nueva literatura "no todo es evidente, sino que se introducen indicios, señales metafóricas cargadas de significado" (Qaffáx). Por otra parte, la

\footnotetext{
${ }^{16}$ He tomado las opiniones que se incluyen a continuación de la entrevista mantenida por Luz Gómez García con cuatro jóvenes narradores egipcios, todos ellos nacidos en los años 60: Sáhar al-Mugui, Mustafa Dhikri, Muntasir al Qaffáx y Miral al-Tahawi (respeto la transcripción dada por la autora). L. Gómez García, "Nueva narrativa egipcia; presentación y entrevista”, Nación Arabe, 45, año XV (verano 2001), pp. 137-145. A continuación de la entrevista, se incluye un relato breve, traducido del árabe al castellano, de cada uno de los autores, ilustrativo de su estilo: Sáhar al-Mugui, "Detrás de las paredes", traducción de Mónica Carrión (pp. 146-147); Mustafa Dhikri, "Divagaciones en un laberinto gótico", traducción de Cristina García Cecilia (pp.148-151); Muntasir al Qaffáx, "Un hombre va de compras", traducción de $\mathrm{M}^{\mathrm{a}} \mathrm{D}$. López Enamorado (pp. 151153); y Miral al-Tahawi, "Una historia”, traducción de Luz Gómez García (p. 154).
} 
brevedad de los textos es fruto de la época de pureza que vive hoy la novela, "pureza en el sentido formal, estético" (Dhikri). Los motivos elegidos no son grandes historias, sino momentos muy concretos, decisivos.

- Esa brevedad requiere un lector crítico. Señala Tahawi en ese sentido: “(...) Necesito un lector muy concreto, dispuesto a adentrarse en decodificaciones variadas, porque el texto es muy breve". Un lector al que Qaffáx se refiere diciendo: "Al escribir, lo que se busca es provocar reacciones en el lector. En cuanto a si esto conlleva transformaciones del tejido narrativo, lo cierto es que muchos de los textos que se escriben hoy en día intentan incorporar de una manera u otra al receptor, hasta el punto de que yo diría que es una especie de moda".

- Todos los autores de los que hablo aquí, dos mujeres y dos hombres, declaran conocer bien la literatura occidental, ya sea a través de traducciones al árabe (Dhikri, Qaffáx, Tahawi), ya sea en la lengua original (Mugui es profesora de literatura inglesa). En este sentido apunta Miral al-Tahawi: "En nuestra relación con la tradición occidental es muy importante que todos nosotros somos lectores de literatura occidental y (...) tratamos con ella tanto sirviéndonos de autores y universos literarios como ahondando en el nivel humano e intelectual, de manera que el conocimiento puede a la fascinación o al miedo".

- Por lo que respecta a la incorporación de las mujeres a la literatura árabe, fenómeno muy notable en los últimos años, hay que señalar que la crítica árabe se ocupa poco de ellas, a la vez que los críticos extranjeros buscan más en el texto la voz de la autora que el análisis del texto en sí (Tahawi). "A la mayoría lo que le importa es que tal o cual novela refleja una experiencia parecida a la propia y eso es lo que se traslada al artículo [de prensa], sin que se dedique atención alguna a cuestiones estéticas o de profundización en cualquier otro sentido que no sea el meramente sociológico" (Qaffáx). En general, los autores jóvenes se quejan de la dificultad para obtener cierto reconocimiento de los críticos por su enfoque tan diferente al de los autores de generaciones precedentes, más orientados hacia los valores clásicos de la novela, que giran en torno a cuestiones sociales. Para Dhikri "el tipo de novelas únicamente preocupadas por lo social y lo político está agotado". Frente a esto, Qaffáx señala que "son los valores internos y la intrahistoria de la novela lo que debe preocuparnos".

Estos son los debates que la más joven literatura egipcia plantea. Y en estos debates participa también May Tilmisani, la autora cuya novela es ahora objeto de nuestra atención. 


\section{MAY TILMISANI.}

Nacida en El Cairo en 1965, es considerada una de las figuras de la nueva generación de escritores egipcios ${ }^{17}$. Tras un año en París, en 1991 comenzó a publicar sus primeros relatos breves en revistas literarias. En 1995 completó sus estudios en la Universidad de Ayn Shams, en El Cairo, especializándose en literatura francesa. Ha impartido docencia en diferentes instituciones (19881998), ha sido locutora en Radio Cairo y se ha dedicado a la crítica cinematográfica.

Desde 1991 ha publicado un buen número de traducciones al árabe, tanto obras literarias como de cine. En 1995 y 1998 publica las colecciones de relatos Esculturas repetitivas ${ }^{18}$ (Naht mutakarrir) y Traiciones mentales (Jiyânât zinniya), a las que siguen sus dos novelas Duniazad (1997) y Heliópolis (2000). Ha escrito guiones de cine, un importante número de estudios sobre cine egipcio e internacional, $\mathrm{y}$ ha colaborado en revistas de arte, como Adab wa Fann (Literatura y crítica), al-Kawâkib (Las Estrellas) y al-Fann al-Sâbici (El Séptimo Arte). Ahora prepara su doctorado, centrado en el cine egipcio, en la Universidad de Montreal, donde reside habitualmente y trabaja como profesora de literatura comparada.

Desde 1996 ha participado como escritora y como crítica de cine en diferentes foros internacionales, en Egipto, Marruecos, Francia. Dinamarca, España, Países Bajos, Alemania y Canadá.

Su novela Duniazad ha sido muy alabada por eminentes críticos egipcios, como Ali al-Rai, Sabry Hafez, Amina Rachid o Salah Fadl. Pero su éxito no ha sido sólo en Egipto. A principios de 1999 esta obra fue seleccionada para ser traducida a diferentes lenguas europeas en el marco del programa Memorias del Mediterráneo, de la Fundación Europea de la Cultura ${ }^{19}$.

\footnotetext{
${ }^{17}$ He tomado la mayor parte de estos datos del detallado curriculum de May Tilmisani publicado en <http://www.arabworldbooks.com/authors/may_telmissany.htm> (última consulta: 07.07.06), así como de referencias dispersas en diferentes páginas web.

${ }^{18}$ Obra a la que alude en Duniazad, p. 59.

${ }^{19}$ Un detallado recorrido por este proyecto europeo puede verse en: $M^{a} \mathrm{D}$. López Enamorado, "Memorias del Mediterráneo: Un espacio europeo para la nueva literatura árabe”, Estudios Filológicos Alemanes, 3 (2003), pp. 423-435.
} 


\section{DUNIAZAD COMO OBRA POSMODERNA.}

Llega así la pregunta que generó este trabajo: ¿Es Duniazad una novela posmoderna? A mi modo de ver la respuesta es sí. Duniazad refleja un amplio conjunto de elementos posmodernistas que analizaré a continuación.

En cuanto al contenido, se trata de una novela de corta extensión: un libro de pequeño formato, con noventa y tres páginas en la versión castellana, divididas en once capítulos. En ella se narra, esencialmente desde la perspectiva de la madre, la pérdida de una hija, Duniazad, que muere sin llegar a nacer, en el vientre materno; el intenso dolor posterior a esta muerte; y los intentos por superarlo. El texto está narrado en primera persona, aunque no siempre se trata del mismo narrador, sino que se produce una alternancia, sólo en los cuatro primeros capítulos, entre el punto de vista de la madre (voz autobiográfica femenina) y, en mucha menor medida, del padre, de forma a veces confusa, si no fuera porque estos cambios de focalización están marcados en el texto con letra cursiva. En el capítulo tres se oye brevemente la voz de otro personaje, una amiga, Nora. En cualquier caso, insisto, prácticamente toda la narración está en primera persona.

Estos fragmentos, nada homogéneos, recomponen (y no de forma total; es innecesario ${ }^{20}$ ) el mosaico de sensaciones y sentimientos de una madre ante la pérdida de una hija, con toda esa carga de soledad, inseguridad y frustración que son señas de identidad de la novela (y de la sociedad) posmoderna. Esta mencionada fragmentación, que es otro de los rasgos que pueden caracterizar a Duniazad como tal novela posmoderna, se aprecia no sólo en el cambio de voz. También es evidente en los bruscos e inesperados cambios de espacio o de tiempo, y, sobre todo, en la inclusión de anécdotas sin aparente relación con el tema central de la novela. Sin embargo, en mi opinión, su función es clara: justamente muestran de nuevo esa desazón y esa angustia que encajan con la posmodernidad. Precisamente la anécdota que para mí es más significativa aparece en el capítulo que lleva por título "El juego de la muerte", donde se narra un episodio en el que Lucky Luke es manteado por unos cowboys, y posteriormente embadurnado de alquitrán y plumas de gallina. Tras esta experiencia, tú, Lucky Luke, "has aprendido el juego de la muerte y te sabes de memoria sus ritos iniciáticos. Te has convertido en un hombre de verdad" ${ }^{\text {. }}$

\footnotetext{
${ }^{20} \mathrm{Si}$ la realidad es incompleta, la novela ha de ser incompleta también.

${ }^{21}$ Duniazad, p. 52.
} 
Toda esta anécdota es una metáfora cuyos referentes son fáciles de identificar. Y su inclusión, entre otros fragmentos similares, quiebra la unidad de la obra:

"Una gran sábana blanca. Cuatro hombres, tal vez más, la sujetan por los extremos. Te lanzan hacia arriba y luego te recogen gritando. Tú te quedas sin aliento, con la mirada perdida. Cada vez que llegas arriba, que ahora desde el suelo te parece tan alto, se te sale el corazón por la boca. Piensas: ¿cuándo terminará el juego de la muerte? ¿Cómo te moverás cuando estés en tierra? (¿Has leído alguna vez los tebeos de Lucky Luke?)

Un barril lleno de aceite o de alquitrán. Unos cuantos cowboys, rudos y socarrones, se han fijado en ti, ¡forastero!, recién llegado a su ciudad olvidada en el desierto. Te mantean en una tela blanca cerca del barril donde luego te sumergirán para después echarte a un inmenso montón de plumas blancas de gallina que se te quedarán pegadas. Te dan náuseas. Te conviertes en un gallo, desgraciado y lleno de plumas ( $\mathrm{i}$ Te acuerdas ahora de los tebeos!).

Te bañas en el hotel. Se te va ese olor a alquitrán, y el susto. De pie, bien firme, te abrochas los botones que adornan tu chaleco marrón. Aguantándote las ganas de vomitar, sales a la calle desértica, orgulloso por tu victoria. Algunos se apartan al verte y otros se burlan de tu frialdad inglesa. Pero ahora has aprendido el juego de la muerte y te sabes de memoria sus ritos iniciáticos. Te has convertido en un hombre de verdad. Ahora puedes fumarte un cigarrillo de liar, y dejarlo colgando, con premeditación, de la comisura de los labios. Sí, introduce tu mano en el estrecho bolsillo del chaleco y atisba el horizonte lejano. Piensa, ahora eres el mismísimo Lucky Luke. No te falta más que un buen caballo, flaco, que comparta contigo el silencio, el ensimismamiento, la aventura y la soledad. Ahora has vencido a esos cretinos. Eres su señor. Ya nadie podrá atarte a cuatro estacas bajo el sol del desierto. Ni derramar sobre ti miel para que te devoren las hormigas. Nadie podrá llevarte a un desfiladero para arrojar sobre ti y tu caballo un caldero de aceite hirviendo. Nadie osará molestarte cuando bebas whisky en la cantina abarrotada de idiotas. Además, puedes coger a tu chica -que lleva un vestido rojo bordado en negro brillante- de la cintura y besarla en la boca delante de todos. Te envidiarán y nunca más se acercarán a ella cuando tú estés de viaje. También podrás dejar el hotel sin pagar la cuenta y sin escolta. Volverás, volverás a las páginas de tu viejo tebeo titulado El juego de la muerte. 
Tal vez en francés no se llame así. Leí las historietas de Lucky Luke a los doce años. Pero todavía recuerdo detalles del juego que una tarde, no hace mucho, me cogió por sorpresa..."22

Pero esta anécdota nos lleva a reflexionar sobre otro elemento característico de la novela posmoderna: el regreso de la tradición que, en el caso de esta novela, se hace presente a través de la intertextualidad ${ }^{23}$. Uso de ésta es la referencia mencionada más arriba al personaje de cómic, el solitario cowboy creado en 1946 por Morris ${ }^{24}$. El episodio que se narra en Duniazad remite precisamente a "las páginas de tu viejo tebeo titulado El juego de la muerte"; título de una entrega de Lucky Luke que a su vez da nombre a este capítulo de la novela egipcia Duniazad, en una clara intertextualidad. Percibo en estos fragmentos un matiz tragicómico destacado, a la vez que una deliberada voluntad de parodiar.

Esta intertextualidad, y esa afinidad con la tradición, ese juego con las formas del pasado ${ }^{25}$ es igualmente patente aquí desde el propio título de la obra, Duniazad, nombre propio de la hijita muerta en esta novela, y nombre propio también de la hermana pequeña de Shehrezad, cuyo papel en las Mil y una noches es muy reducido pero fundamental: debe pedir a su hermana, cuando el sultán haya consumado el acto sexual con ella, que cuente "una de esas maravillosas historias...." Duniazad es la que da paso a las historias, pero no tiene otra voz en las Mil y una noches. Tan sólo reaparece con algún protagonismo tras consumarse la noche mil una, cuando se casa con el hermano del sultán. Este personaje de la tradición árabe no tiene voz, al igual que no tiene voz la Duniazad de May Tilmisani, cuyo nombre sólo ha sido utilizado para rellenar el certificado de defunción. Duniazad es sólo un nombre. Un significante sin significado, un

\footnotetext{
${ }^{22}$ Duniazad, pp. 51-53.

${ }^{23}$ En este sentido, es interesante la obra de G. Genette, Palimpsestos: la literatura en segundo grado (Madrid: Taurus, 1989), donde se define la intertextualidad como la capacidad de un texto de comentar otro texto, bien mediante la imitación, bien mediante la transformación de un modelo literario anterior; o, dicho de otro modo, la relación de un texto con otro por cita, plagio o alusión. Según Genette, el texto literario posterior también influye en nuestra interpretación de ese otro texto que lo precede y al que alude.

${ }^{24}$ Maurice de Bévère, más conocido como Morris, nació el 1 de diciembre de 1923 en Courtrai, Bélgica. A finales de 1946 creó a Lucky Luke, el conocido cowboy solitario que recorre el Oeste ayudando a todo aquel que lo necesita.

${ }^{25}$ Esta es una de las características que menciona Amalia Quevedo como propias de la literatura posmoderna. A. Quevedo, op. cit, p. 20.
} 
término que remite a una realidad que no ha llegado a ser, a un no-ser, a una norealidad.

Duniazad, el personaje de las Mil y una noches, es también traída desde el pasado por el norteamericano John Barth, dando título a uno de los tres relatos de su obra Quimera ${ }^{26}$, en la que un genio (el propio Barth) se aparece a esta joven $y$, entre otras cosas, intercambia con ella secretos sobre el arte narrativo. Barth explora las relaciones entre Shehrezad, el Sultán y su hermana Duniazad, dejando patente su atracción por los cuentos tradicionales, a los que se acerca con una clara ironía e irreverencia típicamente posmodernas. Tradición e intertextualidad se dan de nuevo cita aquí.

Otra de las características destacadas de la novela posmoderna es la mezcla de elementos, la estética del collage, del parche. Señala África Vidal que "la unión de elementos inconexos da lugar a una nueva realidad, a un arte que refleja fielmente el caos en el que vivimos; a nuestra forma de entender el mundo y de acumular experiencias” ${ }^{27}$. Anécdotas aparentemente triviales, que narran insistentemente cosas pequeñas, mezcladas con hechos de enorme dramatismo. En ese sentido, también en Duniazad se mezclan elementos propios de otras disciplinas estéticas. En el último capítulo de la novela, que lleva por título "Punto de inflexión", la autora incluye unos fragmentos con el estilo propio de un guión de cine:

Una escena de la película: el marido se acerca a su mujer. Ella no lo ve. Está ocupada cosiendo un vestidito para su hija. Le clava en el cuello los colmillos insaciables. La bella mujer se transforma en un fantasma blanco exangüe.

Otros planos posibles: La mujer clava a su vez los dientes en el cuello de su bija, que no puede pedir ayuda a los vecinos porque el castillo está apartado del mundo. Los fantasmas se divierten en el jardín posterior.

Escenas de otra película: Los fantasmas no copulan. Tampoco se aburren, pueden volar sobre castillos encantados, atravesar las paredes y cantar en las sombras de la noche con voz melancólica ${ }^{28}$.

En Duniazad somos igualmente testigos de un fenómeno posmoderno: la mezcla entre lo real y lo ficticio, lo vivido y lo soñado, lo racional y lo irracional, cuyos límites no siempre están claros. "El lenguaje posmoderno ya no diferencia

26 Obra escrita en 1972. Traducción castellana por Verónica Head (Madrid, Fundamentos, 1976).

${ }^{27}$ Á. Vidal, Hacia una patafísica de la esperanza. Reflexiones sobre la novela posmoderna (Alicante, Secretariado de Publicaciones, Universidad de Alicante, 1990), pp. 114-115.

${ }^{28}$ Duniazad, pp. 88-89. La cursiva es del texto. 
lo verdadero de lo falso, la ilusión de la apariencia" ${ }^{29}$. Así, en esta novela hay referencias a hechos reales, e incluso a nombres propios de la vida intelectual egipcia de hoy. Es éste el caso de la alusión a Hamid Nasr Abu Zayd, a quien yo misma tuve el placer de conocer en El Cairo en $1991^{30}$. Y todo ello mezclado con ensoñaciones, fantasías, imágenes soñadas, objetos y personajes inventados, conviviendo con la realidad. El siguiente fragmento es una buena muestra de esa confusión en la que discurre la existencia de la narradora:

Como reptiles prehistóricos de cola grande y cabeza pequeña, como en un extraño sueño, veía las caras de mis compañeros de trabajo. Me palpé el trasero, temiendo por un instante que me hubiese crecido una cola prehistórica $^{31}$.

Esa mezcla confusa entre lo real y lo imaginado se infiltra en la realidad cotidiana, transmitiéndole un carácter ilusorio que es patente a lo largo de toda la novela. La narradora presencia, así, la venta de su casa o la limpieza de la misma ${ }^{32}$ como una realidad a la que ella es completamente ajena, a la que asiste como espectadora muda y anestesiada, impasible, incapacitada para intervenir.

Escribir se convierte entonces en una de las formas de crearse a uno mismo, de olvidar, de re-nacer. La escritura es la que salva de la muerte a Duniazad. Y a su madre. La escritura sustituye a la realidad, sublimándola. Y en este sentido abundan en Duniazad referencias a la propia escritura, que es escape y sustituto de la realidad. "Ella era Duniazad, aunque a partir de hoy no será más que estas pocas líneas" ${ }^{33}$, dice la narradora, planteándose, como cuestionamiento claramente posmodernista, el poder de la palabra escrita:

Es hora de deshacerse lentamente del pasado. Apuntalo mi corazón con tablas de madera para que no se desmorone. Entre la abertura de la garganta y la del útero tiendo hilos de amor. ¿Por qué siento que me asfixio cuando pienso que fui su "tumba"? Cierro mi útero a la menstruación que viene y que, a pesar de todo, deseo que llegue.

\footnotetext{
${ }^{29}$ Á. Vidal, op. cit, p. 128.

${ }^{30}$ Hamid Nasr Abu Zayd, profesor egipcio. Objeto de duras críticas y persecuciones judiciales instigadas por parte de algunos sectores islamistas, vive exiliado con su esposa en Leiden. Ver Duniazad, p. 79, nota.

${ }^{31}$ Duniazad, p. 38.

${ }^{32}$ Duniazad, pp. 43 y ss. y pp. 61 y ss.

${ }^{33}$ Duniazad, p. 28.
} 
Escribo acerca de la espera. Acerca del miedo que produce que otro ser crezca dentro de ti, en medio de uno de esos vasos capilares que contienen uno de esos familiares espermatozoides que se nos parecen.

O escribo acerca de la memoria engañosa, que todavía conserva un rostro azul sobre la superficie del cielo azul..., que ocupa el lugar del Paraíso. ¿Dónde está si no el "Señor del trono"? ¿Cuántos kilómetros lo separarán del rostro redondo de Duniazad?

O escribo acerca de cómo vencer un miedo con otro miedo. El miedo a que se te manche la ropa mientras estás con un grupo de gente estirada y bien arreglada.

Tener miedo por cómo habrás salido en la televisión cuando la entrevistadora te preguntó: ¿Qué querías decir con el título Esculturas repetitivas? Tener miedo, cada día, a leer los periódicos por si se han olvidado de mencionar tu nombre en las páginas culturales; ese miedo que te lleva a llamar a una amiga para preguntarle por sus hijos y así cerciorarte de que esa tarde te vio en la televisión.

O escribo acerca de otras soluciones alternativas. Acerca de un amor alternativo, de una aventura alternativa a la de la creación. Es como si te hubieses metido en una historia cómica y forzaras la risa en medio de personajes pálidos y desconocidos... Como reírse de un anciano haciéndole creer que todavía puede coger su bastón para cruzar una calle de veinte metros de ancho... Como jugar a ser la mujer madura que ha pasado de los treinta sin que le afecte y ya puede desabrocharse los botones de la blusa sin sentir vergüenza.

Ahora escribo de cualquier cosa, menos de la muerte. He perdido el cómputo de los días. Una nube blanca atraviesa el rostro azul en el cielo azul. Atraigo a mi marido hacia la cama con un auténtico gesto de libertina. Para hacer un nuevo niño... que no muera... Heme aquí... escribiendo de nuevo el verbo morir ${ }^{34}$.

Quiero referirme brevemente a los personajes de la novela Duniazad. Pocos, muy pocos son descritos con cierta minuciosidad. Ni siquiera es fácil señalar exactamente cuántos son, porque están, en su mayor parte, tan sólo esbozados. De ellos conocemos datos tan dispersos que no podemos recomponerlos, algo que sí era factible en la novela de etapas anteriores. "No he pronunciado el

${ }^{34}$ Fragmentos extraídos de Duniazad, pp. 58-60. En este fragmento May Tilmisani hace referencia a otra de sus obras, Esculturas repetitivas, como ya he señalado en nota 18. 
nombre de mi marido", dice la autora en los últimos párrafos de la obra ${ }^{35}$. Nuevamente volvemos al concepto de la fragmentación, rasgo que, como señalé más arriba, puede caracterizar a Duniazad como novela posmoderna. Sin embargo, y frente a esta nebulosa de personajes tan sólo esbozados, Duniazad ocupa el centro absoluto. Ella vive en un presente continuo precisamente porque no es, no existe ni ha existido nunca. Su tumba ha sido su madre. Jamás vivió. Es el símbolo de la no-existencia. Pasó de la tumba del vientre a la tumba de la vida. May Tilmisani centra la novela en un personaje que es el no-personaje, porque nace muerto. Duniazad nunca ha estado viva, es un reflejo, una ilusión. No tiene realidad. Ni siquiera puede morir porque ya está muerta. Esta niña es la creación de su madre, y la creación de su narradora. Y a la vez es el pretexto de la novela. Hay aquí un juego lúdico, a la vez que trágico, entre la ficción y la realidad. El camino a la esperanza, representado por un nuevo embarazo, aún es desconocido, y aún puede no ser. Duniazad, al igual que el arte posmoderno, plasma lo concebible pero no representable, a través de un proceso de abstracción por el que la autora recrea la imagen de la hijita nunca vista, nunca nacida, nunca viva.

Teniendo en cuenta todos los rasgos analizados en este estudio, podríamos concluir diciendo que la novela Duniazad, de la egipcia May Tilmisani, cumple con las condiciones necesarias para poder clasificarla como novela posmodernista. Aunque otras no se cumplan en absoluto. Tampoco es necesario. Sin embargo prefiero terminar destacando que esta obra, por encima de todas las clasificaciones, es una reflexión sobre el amor y el dolor, sobre la vida y la muerte, sobre la frustración y la esperanza. Una reflexión sobre sentimientos eternos que, en la posmodernidad o fuera de ella, son inseparables del ser humano, sea cual sea el lugar y el tiempo en el que le toque nacer, vivir, escribir o morir.

$\mathrm{M}^{\mathrm{a}}$ Dolores López Enamorado

mdlopez@us.es

Área de Estudios Árabes e Islámicos.

Depto. Filologías Integradas

Facultad de Filología (Universidad de Sevilla)

C/Palos de la Fra. s/n

41004 Sevilla (Spain)

${ }^{35}$ Duniazad, p. 92.
Fecha de recepción: 09/07/ 2006

Fecha de aceptación: 02/02/2007 